\title{
O MODELO ESTRUTURAL DA SUSTENTABILIDADE: UMA DISCUSSÃO ACERCA DOS ELEMENTOS, HIERARQUIA E REPRESENTAÇÃO DO SISTEMA AMBIENTAL
}

\author{
THE STRUCTURAL MODEL OF SUSTAINABILITY: A DISCUSSION ABOUT ELEMENTS, \\ HIERARCHY AND REPRESENTATION OF THE ENVIRONMENTAL SYSTEM
}

\author{
Emilia Alibio Oppliger \\ Izabela Cristina Barbosa Prado de Souza Ronda \\ Ademir Kleber Morbeck de Oliveira
}

\section{RESUMO}

O conceito de sustentabilidade é baseado em três pilares: ambiental, social e econômico, todos com igualdade de importância, interdependentes, tendo como meta atender às necessidades humanas sem degradar o ambiente, garantindo sua preservação para as futuras gerações. Porém, é necessário compreender como esses pilares interagem entre si. Objetivou-se revisar esse conceito e apresentar um novo modelo estrutural de sustentabilidade, em que se compreende 'sistema ecológico' como a natureza sem o ser humano. Trata-se de um artigo teórico, fundamentado na teoria geral dos sistemas, referenciado em análises críticas sobre sustentabilidade e relação entre natureza, sociedade e economia. Demonstrou-se que o sistema ecológico é o mais importante na representação da sustentabilidade, pois se autorregula e não depende dos demais. Conclui-se que há uma hierarquia entre os sistemas e que o sistema ambiental é a soma dos sistemas ecológico, sociocultural e econômico.

Palavras-chave: Teoria geral dos sistemas. Sistema ecológico. Ecossistema. Desen volvimento sustentável.

\section{ABSTRACT}

The concept of sustainability is based on three pillars: environmental, social and economic, all equally important, interdependent, with the goal of meeting human needs without degrading the environment, ensuring its preservation for future generations. However, it is necessary to understand how these pillars interact with each other. The objective was to review this concept and present a new structural model of sustainability, in which 'ecological system' is understood as nature without the human being. It is a theoretical article, based on the general theory of systems, referenced in critical analyses on sustainability and the relationship between nature, society and economy. It has been shown that the ecological system is the most important in representing sustainability, as it is self-regulating and does not depend on others. It is concluded that there is a hierarchy between the systems and that the environmental system is the sum of the ecological, socio-cultural and economic systems.

Keywords: General systems theory. Ecological system. Ecosystem. Sustainable development. 


\section{INTRODUÇÃO}

Compreender a natureza é um dos grandes anseios do homem. Muitas vezes, porém, essa compreensão confunde-se com o ato de dominar o ambiente natural. O ser humano iludiu-se com a crença de que toda a sua criação no campo do conhecimento e da tecnologia pode ser instrumento de controle dos fenômenos naturais (BACON, 1984).

O universo está em constante movimento e evolução. A experiência da temporalidade é confirmada pelas leis da física e de outras ciências. Submetidas às leis do tempo, as leis da natureza apresentam um novo significado: tratam de possibilidades, não mais de certezas, que determinam a realidade do que está por vir, em um fluxo permanente e movimento ininterrupto, atuando como lei geral do universo. O diálogo entre homem e natureza dá-se por meio dessa condição. O ser humano não apenas faz parte da natureza como também depende dela para sua existência. A natureza pode continuar sem o ser humano (PRIGOGINE, 1996).

O caos em quase todas as grandes cidades do mundo é resultado de uma soma de fatores e de uma complexa problemática que requer soluções urgentes como a violência urbana, a falta de planejamento e gestão, a poluição, a escassez dos recursos naturais, o congestionamento do trânsito, o crime organizado, a corrupção sistêmica, a desigualdade na distribuição de renda, a falta de acesso à água potável e ao saneamento básico, a fome e a miséria, entre tantos outros.

É visível que há uma relação entre todos esses elementos que constituem a sociedade. Os fatores essenciais dos problemas públicos, dos temas, das políticas e dos programas que podem ser desenvolvidos e aplicados, devem ser vistos, planejados, implementados e avaliados como componentes interdependentes de um sistema total (LOTUFO, 2011; MATA-LIMA et al., 2013; SOTTO et al., 2019).

Toda e qualquer ação que o ser humano tem por hábito, costume e cultura, interfere no próprio sistema social, como também, no sistema ecológico (natureza sem o ser humano), no sistema econômico, e, por consequência, no sistema ambiental como um todo. Considerando que a economia é um sistema criado pelo ser humano e, por isso, subordina-se ao homem (LEFF, 2000).

Dessa forma, ao abordar o tema 'sustentabilidade', questionase o modelo em que os sistemas ambiental, social e econômico têm a mesma importância e peso para o equilíbrio que garante a viabilidade e qualidade de vida no planeta. Além disso, também se questiona a diferença entre 'sistema ambiental' e 'sistema ecológico'. Para isso, é necessário repensar conceitos e compreender cada sistema, seus elementos e de que maneira interagem entre si.

Sob esse ponto de vista, objetivou-se revisar o modelo de sustentabilidade onde os sistemas ambiental, social e econômico são apresentados com base na igualdade de importância entre eles e na interdependência entre si; e discutir o modelo de sustentabilidade em que há hierarquia entre os sistemas que apresentam independência (ecológico) e dependência (sociocultural e econômico).

\section{Procedimentos Metodológicos}

Trata-se de um artigo teórico, de abordagem qualitativa e levantamento bibliográfico (MARCONI; LAKATOS, 2003). Esta pesquisa está referenciada em análises críticas sobre sustentabilidade e rediscute a correlação entre natureza, sociedade e economia (APPOLINÁRIO, 2011). Assim, desenvolveu-se uma abordagem cujos argumentos propõem um novo enfoque e a subversão da racionalidade dominante, representada pelo 'tripé da sustentabilidade'.

O levantamento bibliográfico foi realizado para enfatizar os aspectos que apontam mudanças no objeto e no fenômeno 'sustentabilidade'. Ao sistema econômico, deu-se o caráter de meio de produção criado pelo homem. A teoria geral dos sistemas fundamentou a discussão e a hierarquização dos sistemas complementou o novo modelo estrutural proposto. 


\section{Sustentabilidade Retórica: O Modelo Padrão}

A partir do século $\mathrm{XVI}$, fortemente influenciado pela revolução científica e aprofundado pela Revolução Industrial, o grande ideal da modernidade passa a ser o progresso ilimitado. O sistema industrial produz bens de consumo em grande escala utilizando recursos naturais de forma exploratória, com o objetivo de atender às necessidades e os desejos do ser humano. A natureza, vista como fonte inesgotável desses recursos, gerou muita riqueza para os países imperialistas e colonizadores, ocasionando imensa desigualdade, pobreza e miséria nos países marginalizados e colonizados (BOFF, 2015).

Ao longo da história, a trajetória do capitalismo está marcada pela exploração das regiões mais pobres pelas mais ricas. O colonialismo comprometeu o desenvolvimento das regiões exploradas e acarretou mudanças profundas em suas estruturas sociais, gerando séculos históricos de dependência entre essas nações em relação às potências colonizadoras (DIAS, 2010).

Nesse processo, o consumo é fator decisivo. Produzir de forma crescente, sem considerar agentes externos como a degradação da natureza e as desigualdades sociais, resume os primórdios do sistema econômico de base capitalista. Não se questiona que o processo capitalista/mercantil/industrial trouxe grandes benefícios para a humanidade (melhores condições de vida e saúde, encurtamento das distâncias e aproximação de seres humanos e contato de diferentes culturas, aumento da expectativa de vida e inúmeras comodidades que vão da luz elétrica e da água encanada, passam pelo automóvel e avião, chegando na geladeira, na televisão e na internet) (BOFF, 2015).

No entanto, ao longo da história moderna foi possível observar que o capitalismo não apenas falhou em resolver questões como pobreza e desigualdade, como de fato as acentuou. Observa-se que o capitalismo não só produziu como perpetuou um quadro de adversidades que podem ser vistas, de forma globalizada, ao longo de toda história moderna. O comprometimento da qualidade ambiental no planeta, situações de escassez, o acesso social- mente injusto aos recursos naturais, a degradação ambiental e a distribuição desigual de renda, são exemplos notórios dos efeitos deletérios desse sistema econômico (SILVA, 2005).

No século $X X$, as desigualdades existentes entre várias regiões do mundo e as mazelas sociais decorrentes, tornaram-se sobremaneira explícitas e alarmantes (DIAS, 2010). Apesar da desigualdade ser uma questão inerente à toda história da sociedade humana, na sociedade contemporânea, a miséria desencadeada por ela torna-se inaceitável. Segundo Costa (2010, p. 128), "a razão para essa postura diante de populações excluídas deve-se à ideia de que fazemos parte de uma totalidade que é a humanidade". O processo de globalização, intensificado a partir do século XX, é apontado, ao mesmo tempo, como responsável por exacerbar a situação de desigualdade e, também, como elemento fundamental para a construção de uma ideia de totalidade em relação à humanidade.

A questão ambiental, que emerge no século $X X$ e se consolida no século $X X I$, figura na sociedade contemporânea como um dilema fundamental da humanidade. Ao estudar a identidade no mundo globalizado, Castells (2000) aponta a questão ambiental e, por sua vez, o ambientalismo (movimento político e ideológico que emerge na década de 1960), como uma forma de comportamento coletivo que visa questionar a forma de relacionamento entre o homem e a natureza. O ambientalismo passa a ser uma forma de identidade ao defender a primazia das pessoas como habitantes do mundo e responsáveis por ele (COSTA, 2010). Pode-se afirmar que, mesmo sendo uma problemática profundamente discutida nos últimos cinquenta anos, a questão ambiental atrelada à ideia de desenvolvimento, ainda inspira controvérsias, aparentemente insolúveis (SILVA, 2005).

O conceito de desenvolvimento é, via de regra, associado à ideia de atendimento das necessidades materiais que decorrem da vida em sociedade. Tais necessidades são costumeiramente relacionadas à promoção de melhores condições e qualidade de vida (SACHS, 2007). Na sociedade capitalista, essas demandas são supridas pela produção e consumo de produtos e serviços que não somente atendem como também criam, permanentemente, 
novas necessidades. A maneira como cada sociedade organiza a produção e o consumo para o atendimento dessas necessidades também interfere nas relações estabelecidas pelos sistemas ecológico, sociocultural e econômico (COSTA; TEODÓSIO, 2011).

O consumo sustentável é alcançado a partir das relações sociais estabelecidas no mercado. A concepção deste 'mercado' não é apenas um lugar de troca de mercadorias, mas de interações socioculturais complexas, que abarca aspectos das dimensões indivíduo-sociedade-organizações, todas inter-relacionadas no processo de formação da cultura. Dessa forma, para garantir o consumo sustentável, é imprescindível compreender qual o significado que o consumo tem na vida das pessoas, considerando seus contextos culturais. É possível planejar estratégias para introduzir práticas cotidianas de consumo atreladas a valores sustentáveis simbólicos (OLIVEIRA; CORREIA; GOMEZ, 2016).
Em resposta às demandas socioambientais que se intensificaram após a década de 1970, a sustentabilidade passa a ser um aspecto fundamental ao desenvolvimento; e a prudência ecológica e a equidade social seus princípios éticos. Foi adotada como cerne para a construção de um modelo de desenvolvimento capaz de diminuir a desigualdade social, regular o sistema de produção e consumo de bens e, consequentemente, minimizar o impacto das atividades humanas sobre o meio ambiente. Nessa perspectiva, consolidou-se o modelo de desenvolvimento sustentável, graficamente representado pela relação de interdependência e equilíbrio entre os aspectos ambiental, social e econômico (SACHS, 2009). Ao modelo-padrão de sustentabilidade (que contempla o sistema ambiental, social e econômico), foram propostas meIhorias chamadas de 'tripé da sustentabilidade': ambientalmente correto, economicamente viável e socialmente justo (Figura 1).

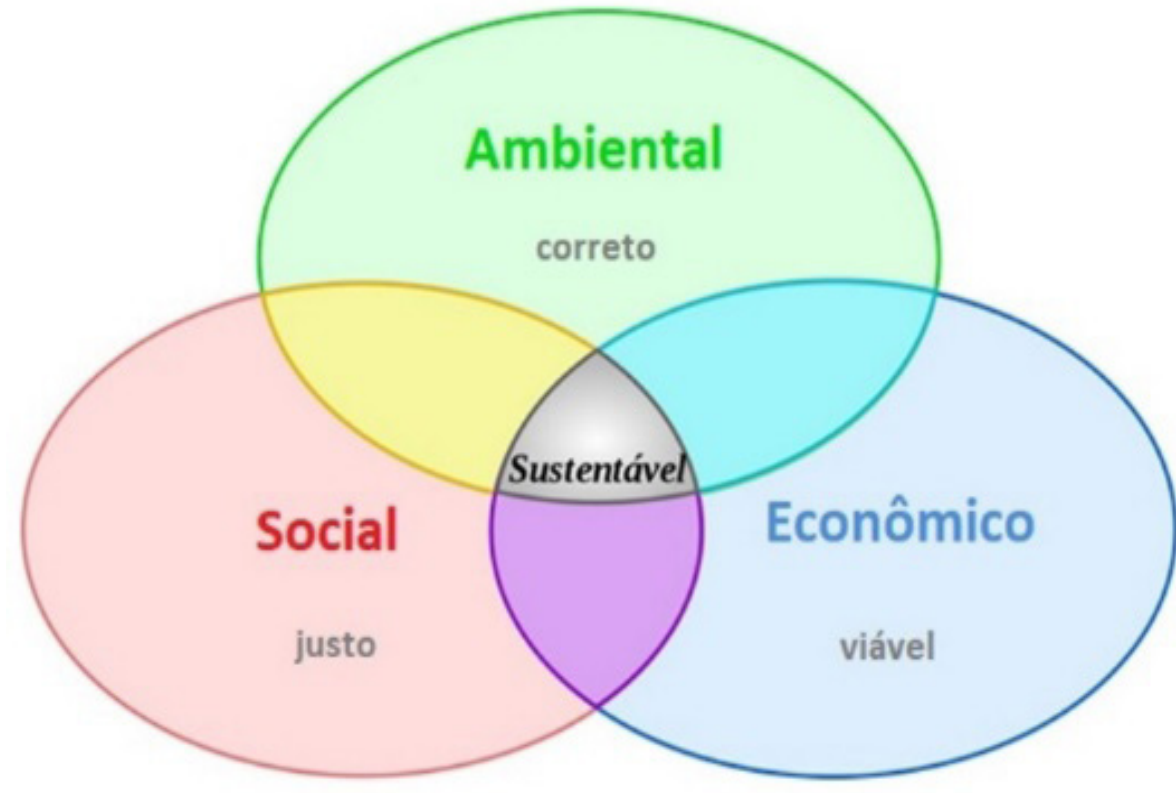

Figura 1 - Representação da integração dos sistemas e o tripé da sustentabilidade

Fonte: Adaptado de Sachs (2009). 
O conceito de sustentabilidade que emerge acrescido de adjetivos (ambientalmente correto, socialmente justo e economicamente viável), passa a ser um caminho para a manutenção da vida humana na Terra. $O$ desenvolvimento que se procura atingir em escala global deve ser socialmente justo, pois os objetivos do desenvolvimento são sempre éticos e sociais; economicamente viável, por que a viabilidade econômica é condição necessária, ferramenta para se fazer avançar em direção à distribuição de renda, no caminho do desenvolvimento includente e sustentável. E ambientalmente correto, pois o desenvolvimento deve ocorrer respeitando-se as condicionalidades ecológicas, a partir do conceito ético da solidariedade diacrônica com as futuras gerações (SACHS, 2009).

Contudo, o sistema de produção e consumo hegemônico não consegue ser socialmente justo e ambientalmente sustentável ao mesmo tempo. Por isso, é impossível que esse modelo, da forma como é proposto, mantenha de pé as três bases do tripé da sustentabilidade, que na verdade se transformou em três proposições conflitantes (MARTINE; ALVES, 2015).

Além disso, apresenta uma grave incoerência: não contempla os elementos humanísticos e éticos. A resposta acerca da sustentabilidade precisa ser buscada por meio de outro entendimento: de que forma se dá a produção, distribuição, consumo e tratamento de todos os resíduos que resultam ao final desse processo. Assim, a sustentabilidade pode ser concebida com base em outros modelos, como, por exemplo, o do 'ecodesenvolvimento', onde a economia deve acompanhar e atender os níveis de preservação e regeneração da natureza; ou mesmo da 'microssustentabilidade', seguindo o modelo da economia solidária, onde o centro é ocupado pelo elemento humano e não pelo capital. Além disso, o trabalho é visto como ação criadora e não como uma mercadoria paga pelo salário; o poder não é centralizado na mão dos proprietários dos meios de produção, mas na autogestão democrática; a competitividade dá lugar à solidariedade; e prima-se pela melhoria da qualidade de vida e do trabalho para todos, não pela maximização do lucro (BOFF, 2015).

\section{Governança Ambiental e o Subsistema Político}

Governança ambiental pode ser compreendida como os processos de interação entre diferentes atores sociais e institucionais na gestão dos recursos naturais, na perspectiva do desenvolvimento sustentável (MERTENS et al., 2011). Refere-se a processos que promovem o debate sobre as expectativas e anseios de diferentes atores sociais, como poder público, iniciativa privada, sociedade civil e comunidade científica, com o objetivo de definir ações a serem implementadas por meio de estratégias de gestão ambiental (LEMOS; AGRAWAL, 2006).

O conceito de governança está relacionado a "padrões de articulação e cooperação entre atores sociais e políticos e arranjos institucionais que coordenam e regulam transações dentro e por meio das fronteiras do sistema econômico". Nesse sentido, incluem-se "não apenas os mecanismos tradicionais de agregação e articulação de interesses, tais como os partidos políticos e grupos de pressão, como também redes sociais informais (...), hierarquias e associações de diversos tipos" (SANTOS, 1997, p. 342).

Rodríguez (2011) afirma que a gestão dos recursos utilizados para a manutenção de toda a vida no planeta é feita por meio da governança, que seria a representação política efetiva de todas as classes sociais. A governança representa o controle da sociedade sobre os investimentos e empreendimentos existentes em determinado tempo e distintos locais. Essa gestão deve reconhecer e representar os interesses da natureza, compreendendo os serviços ecossistêmicos (materiais e não-materiais) que o sistema ecológico oferece.

Serviços materiais estão relacionados aos processos geológicos e biológicos (influência dos oceanos na diminuição de poluentes na atmosfera, das florestas na regulação do clima, das alterações climáticas na quantidade de chuva, da chuva na disponibilidade de água, da água na qualidade do solo e do solo para a produção de alimentos, para citar exemplos mais óbvios). Serviços não-materiais relacionam-se aos hábitos e à cultura de cada sociedade 
(benefícios como recreação física e mental, turismo em áreas naturais, estudos sobre os processos naturais, apreciação estética e enriquecimento espiritual, entre outros) (RODRÍGUEZ, 2011).

Desta maneira, para realmente se atingir o desenvolvimento sustentável, é necessário considerar a chamada governança ambiental como parte do subsistema político, o qual está inserido no sistema sociocultural. Com a governança ambiental representando as ações políticas (refletidas na representação política efetiva de todas as classes sociais), a sustentabilidade pode ser compreendida como a inter-relação dos sistemas:

- Econômico: meio de produção criado pelo homem, capitalismo como modelo predominante, incentivo do consumo, dependente de recursos fósseis, subsídios ocultos e recursos renováveis.

- Sociocultural: seres humanos, sociedade, cultura, tamanho da população, distribuição espacial e do poder, ingresso das classes sociais em diferentes estruturas socioeconômi-

ambiental.

- Ecológico: atmosfera, recursos naturais e biodiversidade.

\section{A Teoria Geral dos Sistemas e o}

\section{Ecossistema: Ponto de Partida para uma}

Nova Representação da Sustentabilidade

Em todos os campos do conhecimento, existe a necessidade de se lidar com complexos chamados 'totalidades' ou 'sistemas'. Isso implica uma fundamental reorientação do pensamento científico. É necessário estudar não somente partes e processos isoladamente, mas também percorrer o caminho inverso e encontrar uma forma de resolver os problemas em sua organização e na ordem que os unifica, resultante da interação dinâmica das partes. Essa percepção é diferente quando o tema é estudado isoladamente ou tratado no todo (BERTALANFFY, 1975).

Por 'sistema', compreende-se uma rede de relações entre diferentes partes, elementos ou componentes que interagem entre si e influenciam um ao outro por meio da troca de energia, matéria ou informação (CHRISTOFOLETTI, 1979). A 'Teoria Geral dos Sistemas', proposta por Bertalanffy (1975), tem por objetivo a formulação de princípios válidos para os sistemas em geral, qualquer que seja a natureza dos elementos que os compõem e as relações ou 'forças' existentes entre eles. Podem apresentar-se na forma de 'sistemas fechados' (física, físico-química, termodinâmica) ou de 'sistemas abertos' (os que abrangem organismos vivos, estabelecendo fluxo contínuo de entrada e saída).

Um sistema pode ser representado e apresenta partes distintas (Figura 2):

- Elementos ou unidades: partes componentes (A, B, C e D).

- Relações: as unidades estão inter-relacionadas, uma dependendo e interagindo com a outra, apresentando fluxos.

- Atributos: são qualidades que caracterizam os elementos do sistema.

- Entrada (Input): constituída por aquilo que o sistema recebe de energia para seu funcionamento. Cada sistema é alimentado por diversos tipos de entrada.

- Saída (Output): o que entra no sistema, sofre transformações e é encaminhado para a saída, representando um resultado.

A Ecologia (conceito criado e descrito por Ernst Haeckel, em 1866) tem base na Teoria Geral dos Sistemas ou Análise Sistêmica (proposta em 1950 pelo biólogo austríaco Ludwig von Bertalanffy). Embora a Ecologia seja anterior à Teoria Geral dos Sistemas, alguns conceitos de sistemas já vinham sendo usados antes do aparecimento formal da Ciência Ecológica, ainda na Biologia. Considerando que o Ecossistema (ou Sistema Ecológico) é um sistema funcional de comunidades com interações complexas entre si (componentes bióticos) e entre componentes não vivos (meio abiótico) e do ambiente (habitat), Ferretti 


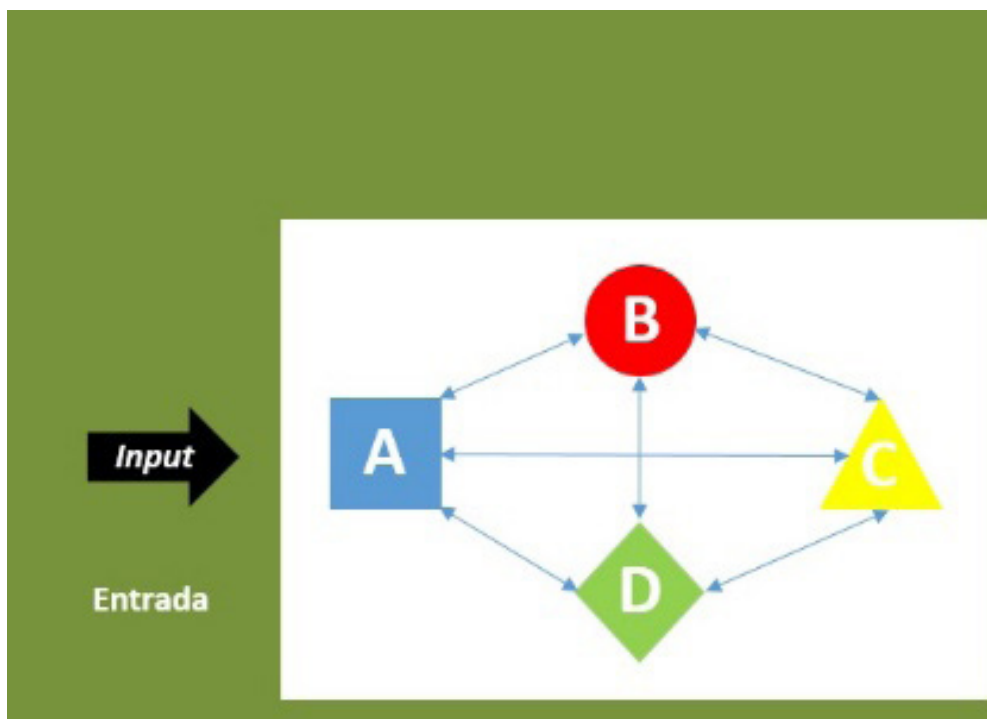

(2002) apresenta os seguintes pressupostos para o Sistema Ecológico:

Interação: ação recíproca que poderá modificar o comportamento dos elementos que compõem o sistema podendo ser, principalmente, uma interação de causa-efeito, temporal ou de retroação.

Organização: refere-se à organização tanto estrutural quanto funcional, que se complementam.

Totalidade: um sistema não é, simplesmente, a soma de elementos que o compõe: é o todo com cada uma de suas partes. Esse conceito é intimamente ligado ao conceito de hierarquia.

Complexidade: o grau de complexidade dependerá do número de elementos que compõem o sistema, o tipo e o número de inter-relações existentes entre eles e sua hierarquização.
O conhecimento em relação às coisas e ao funcionamento do universo, geralmente é utilizado como argumento sobre o valor da ciência e o seu impacto na sociedade e no bem-estar da humanidade. O conhecimento da física para o controle e uso das tecnologias; da biologia para permitir avanços da medicina moderna, onde, por exemplo, estendeu a expectativa de vida muito além dos limites atribuídos aos seres humanos nos séculos passados ou mesmo nas últimas décadas. A aplicação de métodos modernos na agricultura foi capaz de suportar um aumento de população que seria impossível há um século (BERTALANFFY, 1975).

Entretanto, muitas realizações da física, química e biologia são usadas para uma destruição cada vez mais eficiente [armas químicas e biológicas de destruição em massa]. Também há fome em enormes áreas do mundo, enquanto em outras partes, colheitas apodrecem ou são destruídas para obedecer às 'leis do mercado'. 
A guerra e a aniquilação indiscriminada da vida, das culturas e dos meios de manutenção humanos [especialmente da natureza] tornaram-se a saída para as altas taxas de natalidade e da consequente superpopulação (BERTALANFFY, 1975).

É necessário considerar que o sistema ecológico (sem incluir o ser humano) faz parte do sistema ambiental e que, por sua vez, ele também engloba o sistema sociocultural e o sistema econômico, podendo ser compreendido da seguinte forma (Figura 3).

Além do entendimento de que os sistemas ambiental e ecológico (ou ecossistema ou natureza) são distintos, as interferências da cultura e dos hábitos de consumo econômico da sociedade precisam ser consideradas na representação sistêmica da sustentabilidade.

\section{Os Sistemas Sociocultural e Econômico}

A dimensão social se refere à humanidade e sua organização em grupos distintos. Cada grupo recebe diferentes tipos de classificação, de acordo com o tipo de estrutura, civilização, solidariedade, nível de tecnologia, comunicação, sistema econômico e político, unidade linguística, cultura e religião, entre outros (MARTINS, 2013). A combinação dessas diversas variáveis, molda o comportamento de determinado grupo em relação à natureza da qual ele dispõe.

O capital esteve presente desde o início do processo de colonização e manifesta sua especificidade no seu caráter universal. É o capital que determina as relações, que não são intrínsecas nem às

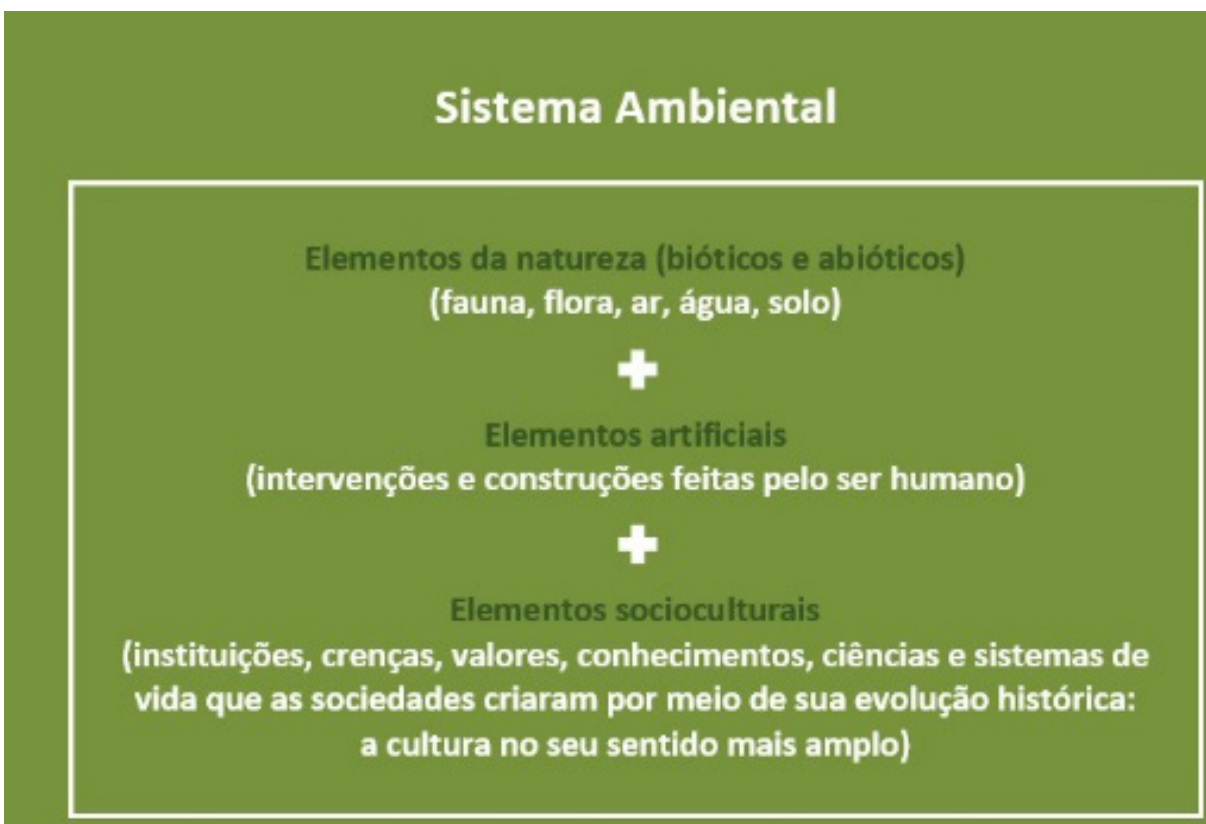

Figura 3 - Elementos que formam o sistema ambiental

Fonte: Adaptado de Casasola (2000) 
nações, nem às regiões. Ele também determina o processo de formação histórico-cultural e rege o processo de desenvolvimento ou crescimento nos quatro cantos do mundo. Entretanto, o movimento universal do desenvolvimento histórico é quebrado por mecanismos ideológicos como o regionalismo, o nacionalismo e o terceiro-mundismo, reforçando a teoria da dependência. $O$ processo de 'mundialização do capital' é marcado pela hegemonia do capital financeiro, que é o resultado da livre concorrência que ocasionou sua progressiva concentração e gerou o monopólio. Dessa forma, o capitalismo chega em sua fase superior, chamada de imperialismo, e define as novas bases do processo de acumulação (IANNI, 1993; CHESNAIS, 2005).

O processo civilizatório universal dá-se pela reprodução ampliada do capital, concentrado e centralizado em diferentes dimensões (local, regional, nacional, continental e internacional). Porém, conceitos são insuficientes para expressar o que está acontecendo em diferentes lugares (três mundos, imperialismo, milagre econômico, Estado-Nação, entre outros), com a globalização atingindo todas as esferas da vida social, coletiva e individual (IANNI, 1993).

A dissolução do Estado representa um governo realizado por transnacionais. Em outras palavras: empresas tomando decisões e influenciando leis e políticas nacionais. As organizações econômicas, políticas e culturais (conglomerados, bancos, mídia impressa e digital, universidades etc.) organizam o mundo em vários níveis, ignorando indivíduos, grupos, classes, movimentos sociais, partidos políticos, correntes de opinião pública, sociedades e estados nacionais. Essas organizações ordenam e reordenam as economias e as sociedades, os povos e as culturas (IANNI, 1993).

A ideia de um Estado, praticamente, nulo (que considera que a regulação não apenas da economia, mas também da sociedade, realiza-se no mercado), é representada pelo neoliberalismo. Sob o argumento da 'ineficiência' do Estado na prestação de serviços, a privatização dos serviços públicos coloca o mercado como regulador da sociedade e o Estado como mero mediador de conflitos. Os direitos públicos e coletivos, transformam-se em 'serviços'; os cidadãos transformam-se em 'usuários', 'clientes' ou 'compradores', e a construção da cidadania é comprometida. Por outro lado, ao mesmo tempo em que o neoliberalismo desconsidera a função do Estado, colocando a soberania nas mãos de organizações e corporações transnacionais, a questão ambiental é sempre limitada à responsabilidade do Estado-Nação (RODRIGUES, 1998).

Paradoxalmente, a crise ecológica de dimensão planetária, marcada pela revolução industrial no continente europeu, alimentada pelo desenvolvimento do sistema capitalista, não deixou de afetar os países socialistas (LACOSTE, 1988). O ano de 1972 foi marcado pela Conferência das Nações Unidas sobre o Meio Ambiente, em Estocolmo, e pelo relatório do Clube de Roma, que definiu 'Os limites do crescimento', afirmando que os recursos naturais do planeta são finitos, com as primeiras discussões acerca do que seria o 'desenvolvimento sustentável' (SCHONS, 2012). Apesar de ser considerado um fenômeno novo, o abismo entre países ricos e pobres, criado durante o processo crescimento econômico moderno, já era evidente. A questão ecológica e ambiental, concretizada pelo saque dos recursos naturais, também 'se globalizou', agravando a desigualdade entre as nações do centro e as da periferia do sistema capitalista (SILVA, 2010).

Neste contexto da exploração dos recursos naturais, o hiato entre nações ricas e pobres foi traduzido por Porto-Gonçalves (2004, p. 129-137) como: "para uns os proveitos e para outros os rejeitos". Para mensurar essa afirmação, no ano de 1820, a distância entre uma pessoa rica no Reino Unido (a principal economia da época) e um pobre da África (região mais pobre do mundo) era na proporção de quatro para um, considerando a renda per capita. No ano de 1998, a distância entre um cidadão rico nos Estados Unidos (principal economia naquele ano) e um pobre da região da África (ainda a região mais pobre do planeta), chegou à proporção de vinte para um (SACHS, 2005, p. 55).

A discussão sobre a problemática ambiental redefine a divisão internacional dos custos ambientais: o aquecimento global, a perda de biodiversidade, o lixo tóxico, o efeito dos agrotóxicos, a contaminação e destruição dos recursos hídricos e a biopirataria (im- 
pactos das transnacionais desconsiderados nos países periféricos) (FOLADORI, 2002). Apesar de a natureza ser considerada um bem comum, está apropriada em forma de territórios e mercadorias de Estados-Nação que, ao se tornarem neoliberais, repassam o 'bem comum' ao controle e uso pelo mercado. O mercado, por sua vez, não só explorou os recursos naturais até a beira dos seus limites como vê, inerte, as necessidades de milhões de famintos, miseráveis e empobrecidos no processo capitalista de produção (RODRIGUES, 1998).

As questões ecológica e social andam lado a lado: o resultado é quanto e como se produz e, quem se apropria dos bens produzidos. Essa correlação é que determina o que é o desenvolvimento, para quê e para quem serve. Já o crescimento, que não considera custos (especialmente para nações periféricas), é calcado em uma produção irracional, cujas consequências levam o planeta a sofrer com diversos problemas, tais, como: chuvas ácidas, poluição dos oceanos por plásticos, contaminação das águas e da atmosfera por produtos químicos, alterações no clima, entre tantos outros exemplos (SCHONS, 2012).

Além dos fatores social e ecológico, os países periféricos que tentam 'crescer' dentro do processo capitalista de produção, estão sujeitos a uma transformação que compromete as dinâmicas demográficas urbana e rural. O capital financeiro redireciona processos demográficos por meio das commodities (minérios, petróleo, grãos, carnes e celulose), a urbanização se interioriza, áreas naturais são antropizadas, florestas são derrubadas e descaracterizam terras indígenas e de comunidades tradicionais. 0 agronegócio representa a acumulação no campo, envolvendo o capital financeiro das grandes indústrias químicas, de sementes híbridas, fertilizantes, biotecnologia, tratores e maquinários, o que torna a agricultura químico-dependente e transforma a terra em latifúndios de monoculturas para exportação. Como resultado, a exaustão de ecossistemas e a perda progressiva das potencialidades ecológicas, que são transformadas em fonte de acumulação de capitais. Nesse sentido, ocorre a privatização dos ganhos econômicos e a socialização das perdas e danos sociais e ecológicos pelas populações locais atingidas (SILVA, 2015).
Após séculos de exploração da natureza, a interferência humana sobre o ambiente em função das atividades produtivas [economia], passa a ser considerada uma problemática. A partir do final da década de 1960, quando evidenciados uma série de impactos ambientais de alcance global, muitas vezes irreversíveis, são incontáveis os cenários de degradação de recursos, de desigualdade social e econômica e de uma crise ambiental de escala mundial. Esforços são feitos na tentativa de encontrar uma forma para conciliar a economia com a conservação ambiental para a manutenção do equilíbrio dos ecossistemas e da qualidade de vida (POTT; ESTRELA, 2017).

Apesar de ser um fenômeno social, a economia figura como uma dimensão autônoma na teoria geral dos sistemas e na busca pela sustentabilidade. Um sistema econômico é um conjunto de dependências econômicas reciprocamente ligadas que, pelo fato de estarem vinculadas, surgem mais ou menos ao mesmo tempo e se desfazem, também, aproximadamente no mesmo momento, sendo, portanto, um produto social dotado de historicidade (KULA, 1974 apud BARROS, 2012). O sistema econômico também pode ser compreendido como um conjunto de relações recíprocas que os fatos econômicos de determinado tipo estabelecem entre si. Surge em uma determinada sociedade, historicamente localizada. Não é um sistema estático: de um lado apresenta uma dinamicidade própria e uma tendência a se transformar; de outro lado, as transformações podem conduzi-lo, a certa altura, a adquirir uma outra identidade que pouco tem a ver com a situação inicial do sistema (BARROS, 2012).

Na perspectiva antropológica, sociedade e indivíduos são elementos interdependentes, onde o indivíduo vive para a sociedade; a sociedade vive para o indivíduo; e sociedade e indivíduos vivem para a espécie (MORIN; LE MOIGNE, 2000). Nessa relação, o sistema ecológico (desconsiderado o ser humano) existe sem manter relação de dependência com a sociedade, pois a natureza não existe em função da sociedade, do indivíduo ou da espécie. Esse embate contribuiu para a construção do conhecimento fragmentado, que torna dificultosa a análise integrada dos aspectos sociais e naturais e seus reflexos sobre a vida na Terra, 
inviabilizando uma concepção complexa que englobe os aspectos ecológicos, sociais e econômicos na análise sistêmica da sustentabilidade (PÁDUA, 2008).

A teoria geral dos sistemas é retomada nesse contexto. Sua proposta de análise integrada da realidade envolve a natureza, a sociedade e sua cultura e as atividades de produção, não como um todo composto de partes fragmentadas, mas sim como um todo uno e indivisível: o ambiente. No entanto, considerar a totalidade e a complexidade dos sistemas, não consiste em abandonar os princípios de ordem, separabilidade e lógica no pensamento científico, mas sim redimensioná-los, reorientá-los e integrá-los em uma concepção mais rica, que considere a interdependência das relações que se estabelecem em um todo integrado (MORIN; LE MOIGNE, 2000).

O sistema econômico, nos moldes como se conhece hoje, é relativamente novo. O livro 'Riqueza das Nações', de Adam Smith (originalmente publicado em 1776), registra historicamente os primórdios da economia e destaca uma divisão de tempo entre o estado 'rude e primitivo' e o estado em que há 'apropriação da terra e acumulação de riquezas'. Em sua obra, Smith exalta o progresso e contrapõe o homem e a natureza. O humano é identificado como o ser que domina e conquista o universo natural, o que é visto como algo positivo e valoroso. A inversão de valores éticos também é exposta e o egoísmo e a busca racional por interesses próprios são tidos como virtudes que levariam ao bem-estar e à felicidade de todos, por meio de um mercado livre (LEÃO; CARVALHO, 2008).

Para Marx (1989), a estrutura econômica da sociedade é constituída pelas relações de produção. O modo de produção da vida material condiciona o desenvolvimento da sociedade, da política e do intelectual coletivo [o modo de interpretar e compreender as coisas, hábitos, costumes e cultura]. Sobre a economia, erguese a superestrutura política e jurídica, à qual correspondem determinadas formas de consciência social.

Assim, são distintos os pensamentos acerca da sociabilidade no contexto do mercado e da sociabilidade humana. A sociedade econômica vista por Marx, é formada por novas relações entre indivíduos, coletividade e natureza. A distância construída entre os homens é amenizada e é quebrada a lógica de dominação da natureza, implícita na compreensão do progresso [crescimento econômico]. Cada sociedade apresenta seus próprios padrões internos [cultura] e diferentes capacidades de controlar a natureza externa ou formas de se relacionar com a natureza (LEÃO; CARVALHO, 2008).

O crescimento econômico é citado como fator fundamental para promover condições necessárias ao desenvolvimento social e à conservação de recursos, mas também apontado como elemento gerador das desigualdades sociais. $O$ consenso reside no fato de que, para que o desenvolvimento seja possível, deve ser economicamente factível. As taxas significativas de crescimento são necessárias, uma vez que é muito difícil redistribuir bens e renda em uma economia estagnada (SACHS, 2007).

A complexidade dessa questão requer novos métodos de análise para o enfrentamento dos problemas relacionados à sustentabilidade. É necessário promover a aproximação e, a re-união [no sentido de unir novamente, fazer o caminho de volta que levou à fragmentação, segmentação e especialização] do conhecimento científico, viabilizando a interação entre os diferentes campos do saber, além de possibilitar novas formas de produção do conhecimento e o desenvolvimento de outras metodologias para uma ação transformadora da realidade. É preciso romper os obstáculos impostos à articulação das ciências para a construção de um pensamento complexo para a compreensão do mundo e seus aspectos ecológicos, sociais e econômicos (PÁDUA, 2008).

\section{Hierarquia dos Sistemas: Um Novo Método de Análise da Sustentabilidade}

A concepção de uma natureza passiva, submetida a leis deterministas, é uma especificidade do Ocidente. Entretanto, em países orientais, 'natureza' significa 'o que existe por si mesmo'. Enquanto que para os físicos que seguiam Einstein o problema do 
tempo estava resolvido, para os filósofos, ele continuava sendo a questão por excelência, aquela em que estava em jogo a existência humana e sua significação (PRIGOGINE, 1996).

O ponto de partida para essa diferente visão de sustentabilidade é a natureza (sistema ecológico sem o ser humano) como sistema que, diferentemente dos homens e da economia, não se submete às leis da sociedade ou às leis do mercado. Por esse fato, pode ser considerado independente, que se autorregula e, por isso mesmo, o sistema mais importante (CAVALCANTI, 2012).

O ser humano e a cultura, que lhe é inerente [hábitos e costumes, tudo que é criado e cultivado pelo homem e pela sociedade] são compreendidos em um sistema que interfere na sustentabilidade. A economia também é um sistema que, além de impactar de forma contundente na degradação da natureza, promove a desi- gualdade social e interfere na sustentabilidade (ROMEIRO, 2012). Assim, é necessário analisar os conceitos de sistema ambiental, sistema ecológico, sistema sociocultural e sistema econômico, propondo uma nova estrutura para representar a sustentabilidade (Figura 4).

Os desastres ambientais passados e recentes também suscitam dúvidas sobre o modelo de sustentabilidade em que o sistema ecológico tem a mesma importância que os sistemas social e econômico. Por desastres ambientais compreende-se prejuízos ecológicos (extinção de espécies, contaminação de rios por atividades de mineração e garimpo, derretimento de geleiras e diminuição das calotas polares causados pelo aumento na temperatura média global, corte de árvores centenárias e desmatamento de florestas, queimadas e perda significativa de biomas para o avanço

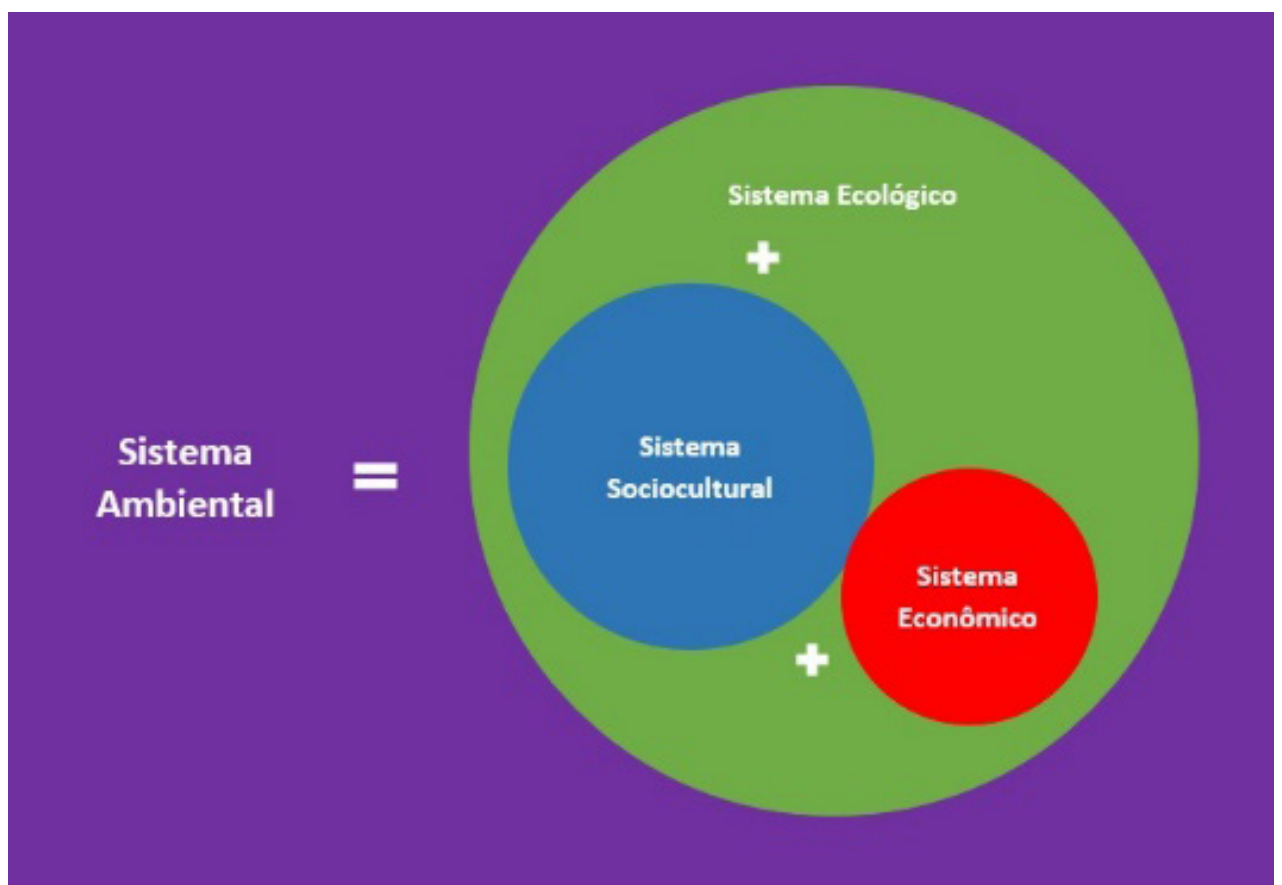

Figura 4 - Modelo estrutural da sustentabilidade: elementos e hierarquia

Fonte: Elaborado pelos autores (2018). 
da fronteira de monoculturas e aumento de áreas de pastagem, por exemplo), socioculturais (comunidades tradicionais afastadas de seus territórios, pessoas que moram em centros urbanos e áreas de risco perdem suas casas em enxurradas recorrentes, as consequências da falta de saneamento básico e o que isso reflete nos hábitos para adaptação às condições adversas, por exemplo), e econômicos (perda ou comprometimento de safras, desperdício de alimentos, reflexo da escassez hídrica na produção, custo e abastecimento de alimentos e insumos, uso de fontes não renováveis de energia em indústrias, por exemplo).

Além disso, do ponto de vista sociocultural, tanto o modelo baseado na importância equânime dos sistemas ambiental, social e econômico, quanto o modelo proposto neste estudo, onde o sistema ecológico é mais importante do que os sistemas sociocultural e econômico, são questionáveis em relação à própria sustentabilidade. Há que se considerar um novo modelo estrutural da sustentabilidade, onde existe hierarquia entre os sistemas e diferença entre sistema ambiental e sistema ecológico. Da mesma forma, para que, de fato, se alcance a sustentabilidade, é necessário reconhecer que o sistema econômico dominante é sustentado pela diferença entre classes sociais. No capitalismo, na forma como é conhecido, ocorre o acúmulo de bens, o consumo irracional, o desperdício e a desigual distribuição da riqueza. A diferença entre classes, por si só, já descaracteriza o princípio do equilíbrio que deve existir em cada um dos sistemas para que haja harmonia no sistema ambiental, como um todo uno e indivisível.

É evidente que as interferências do ser humano na natureza são o principal motivo do desgaste e, muitas vezes, da perda irreversível de elementos do sistema ecológico. Entretanto, é interessante observar que em áreas onde o meio ambiente natural é quase completamente inexistente, especialmente em grandes cidades ou em localidades deficientes de planejamento e gestão, ela se manifesta em descontrole e desequilíbrio: enxurradas e inundações, secas prolongadas e incêndios, ressacas, erosão, pragas, epidemias etc., refletindo diretamente sobre a vida das pessoas.
As relações entre os sistemas precisam ser revistas, considerando toda a problemática apresentada pela natureza e pela sociedade de consumo em suas diversas formas de cultura, influenciada pelo modo de produção dominante. É necessário que se reconheça o domínio da natureza e o sistema ecológico como o mais importante, não só para a manutenção da qualidade de vida, como também, para as ações de governo de planejamento e gestão de políticas públicas e, especialmente, para a continuidade da espécie humana em um planeta com natureza em condições de abrigar e sustentar sociedades e modos de produção.

\section{Considerações Finais}

É preciso fortalecer e ampliar o debate em torno de um modelo de sustentabilidade realista, que considere a complexa inter-relação entre os aspectos ecológicos, socioculturais e econômicos de forma não natural, organizada pelas ações e interesses humanos, com objetivos predominantemente econômicos e políticos. Observa-se que os aspectos socioeconômicos são determinantes para a construção de um modelo de desenvolvimento sustentável que atenda às necessidades da sociedade, influenciada e distanciada por hábitos e possibilidades de consumo.

Somente o modelo que promova o crescimento econômico com impactos positivos em termos sociais e não destrutivos em termos ecológicos, merece a denominação de 'desenvolvimento'. Com relação aos critérios de sustentabilidade social, o crescimento econômico só pode contribuir para o desenvolvimento se for capaz de reduzir a pobreza e as desigualdades sociais. $\mathrm{O}$ crescimento econômico, se colocado a serviço de objetivos socialmente desejáveis e repensado de forma adequada, de modo a minimizar os impactos ecológicos negativos, continua sendo uma condição necessária para o desenvolvimento sustentável.

A contribuição deste estudo está na apresentação do sistema ecológico como sendo o sistema mais importante e independente dos sistemas social e econômico. Além disso, agrega-se o termo 'cultura' (em seu mais amplo significado) ao sistema social, passando a denominá-lo de 'sistema sociocultural', por considerar 
que a cultura é produto e inerente ao ser humano que vive em sociedade. Por fim, propõe-se a diferenciação dos termos 'sistema ambiental' e 'sistema ecológico', o que embasa a apresentação de um novo modelo estrutural da sustentabilidade.

Natureza, sociedade e economia são sistemas regidos por regras ora autônomas, ora dependentes entre si. O desenvolvimento sustentável é o resultado do equilíbrio entre as variáveis que compõem cada um dos sistemas. Nesse sentido, é fundamental fomentar uma análise que faça frente ao modelo padrão de sustentabilidade até então adotado, a fim de demonstrar e reconhecer a importância maior do sistema ecológico frente ao sociocultural e econômico. É necessário redimensionar o grau de importância de cada um dentro da teoria geral de sistemas e contribuir para a apresentação de novas metodologias que possibilitem a construção de ferramentas pertinentes ao enfretamento das questões concernentes à sustentabilidade.

Quando se compreende que o sistema ecológico (a natureza sem o ser humano) se autorregula e não depende dos demais sistemas para sua existência, parece claro que a sustentabilidade tão estudada, proposta e rediscutida, está diretamente relacionada às atitudes dos seres humanos. Os hábitos precisam ser drasticamente mudados em relação à forma de regulamentar, produzir, consumir e destinar os resíduos que resultam das atividades de produção para as condições e a manutenção da qualidade de vida no planeta. Para que se promova a recuperação de ecossistemas comprometidos, é necessário que o sistema econômico seja readequado, utilizando energias renováveis e limpas, por exemplo.

Além da participação de governos, grupos transnacionais, indústrias e empresas, o efeito maior e mais eficiente virá de cada indivíduo. O ser humano precisa redescobrir sua consciência, cobrar mudanças em suas próprias atitudes, praticar sua educação (não apenas produzir e acumular conhecimento) e exercer sua cidadania. Essa pode ser uma saída para a atual escassez e destruição de recursos naturais essenciais à sobrevivência da espécie humana. É preciso evitar o consumismo desnecessário e sem critérios, que resulta em desperdício. Além disso, as desigualdades sociais e a miséria humana devem ser combatidas, pois representam um desequilíbrio incompatível com o desenvolvimento sustentável.

As mudanças de atitude em relação às formas de produção e, especialmente, de consumo, podem refletir significativamente na melhoria da qualidade de vida individual e coletiva. Além disso, é preciso redistribuir os meios de produção e diminuir as desigualdades sociais, evitando todo e qualquer tipo de desperdício, seja de bens materiais, recursos naturais e, especialmente, de alimentos.

Quando o sistema ecológico for compreendido como o sistema mais importante e os esforços para a conservação dos recursos naturais (ar, água e solo) e da biodiversidade surtirem efeito e forem sentidos em escala global, o ser humano terá garantidas não apenas sua existência e sobrevivência como espécie, como poderá desfrutar e proporcionar qualidade de vida para as próximas gerações.

\section{REFERÊnCIAS Bibliográficas}

APPOLINÁRIO, Fabio. Metodologia da Ciência: Filosofia e prática da pesquisa. São Paulo: Cengage Learning, 2011.

BACON, Francis. Novum Organum ou verdadeiras indicações acerca da natureza. Coleção 'Os pensadores'. São Paulo: Abril Cultural, 1984.

BARROS, José D'Assunção. Os sistemas econômicos e suas formas de racionalidades: a busca das singularidades na moderna história econômica e seus novos desafios. Revista de Economia, Curitiba, v. 38, n. 1, p. 109-131, 2012. http://dx.doi.org/10.5380/ re.v38i1.28288

BERTALANFFY, Ludwig von. Teoria Geral dos Sistemas. Petrópolis: Editora Vozes, 1975.

BOFF, Leonardo. Sustentabilidade: o que é, o que não é. Petrópolis: Editora Vozes, 2015.

CASASOLA, Luis. Turismo y ambiente. México: Trillas, 2000

CASTELLS, Manuel O poder da identidade. São Paulo: Paz e Terra, 2000.

CAVALCANTI, Clóvis. Sustentabilidade: mantra ou escolha moral? Uma abordagem ecológico-econômica. Estudos Avançados, São Paulo, v. 26, n. 74, p. 35-50, 2012 http://dx.doi.org/10.1590/S0103-40142012000100004

CHESNAIS, François. A finança mundializada. São Paulo: Boitempo, 2005.

CHRISTOFOLETTI, Antônio. Análise de sistemas em Geografia. São Paulo: HUCITEC, 1979.

COSTA, Cristina. Sociologia: introdução à ciência da sociedade. $4^{\mathrm{a}}$ ed. São Paulo: Moderna, 2010 
COSTA, Daniela Viegas da; TEODÓSIO, Armindo dos Santos de Souza. Desenvolvimento sustentável, consumo e cidadania: um estudo sobre a (des)articulação da comunicação de organizações da sociedade civil, do estado e das empresas. Revista de Administração Mackenzie, São Paulo, v. 12, n. 3, p. 114-145, 2011. http://dx.doi. org/10.1590/S1678-69712011000300006

DIAS, Reinaldo. Introdução à Sociologia. $2^{\text {a }}$ ed. São Paulo: Pearson Prentice Hall, 2010.

FERRETTI, Eliane Regina. Turismo e meio ambiente: uma abordagem integrada. São Paulo: Roca, 2002

FOLADORI, Guillermo. Contenidos metodológicos de la educación ambiental. Tópicos en Educación Ambiental, Cidade do México, v. 4, n. 11, p. 33-48, 2002.

IANNI, Octavio. A sociedade civil mundial. In: IANNI, Octavio. A sociedade global. 2 ed. Rio de Janeiro: Civilização Brasileira, 1993, p. 35-53.

LACOSTE, Yves. A Geografia serve antes de mais nada para fazer a guerra. Campinas: Editora Papirus, 1988

LEÃO, Igor Zanoni Constant Carneiro; CARVALHO, Anna Luiza Barbosa Dias de. Um introdução à história econômica. Economia e Sociedade, Campinas, v. 17, n. 3, 539 548, 2008. http://dx.doi.org/10.1590/S0104-06182008000300008

LEFF, Enrique. Ecologia, capital e cultura: racionalidade ambiental, democracia participativa e desenvolvimento sustentável. (Tradução de Jorge Esteves da Silva). Blumenau: Edifurb, 2000.

LEMOS, Maria Carmen; AGRAWAL, Arun. Environmental governance. Annual Review of Environment and Resources, v. 31, 297-325, 2006. https://doi.org/10.1146/annurev. energy.31.042605.135621

LOTUFO, José Otávio. Oikos: reintegrando natureza e civilização. Revista LABVERDE, v. 2, p. 108-127, 2011. https://doi.org/10.11606/issn.2179-2275.v0i2p108-127

MARCONI, Marina de Andrade; LAKATOS, Eva Maria. Fundamentos de metodologia científica. São Paulo: Atlas, 2003.

MARTINS, Carlos Benedito. Em defesa do conceito de sociedade. Revista Brasileira de Ciências Sociais, São Paulo, v. 28, n. 82, p. 229-234, 2013. http://dx.doi.org/10.1590/ S0102-69092013000200014

MARTINE, George; ALVES, José Eustáquio Diniz. Economia, sociedade e meio ambiente no século 21: tripé ou trilema da sustentabilidade? Revista Brasileira de Estudos de População, Rio de Janeiro, v. 32, n. 3, p. 433-460, 2015. http://dx.doi.org/10.1590/ S0102-3098201500000027P

MARX, Karl. Contribuição para a crítica da economia política. São Paulo: Mandacaru, 1989.

MATA-LIMA, Herlander; ALVINO-BORBA, Andreilcy; PINHEIRO, Adilson; MATA-LIMA, Abel; ALMEIDA, José António. Impactos dos desastres naturais nos sistemas ambiental e socioeconômico: o que faz a diferença? Ambiente \& Sociedade, v. 16, n. 3, p. 45-64, 2013. https://dx.doi.org/10.1590/S1414-753X2013000300004

MERTENS, Frédéric et al. Redes sociais, capital social e governança ambiental no Território Portal da Amazônia. Acta Amazonica, Manaus, v. 41, n. 4, p. 481-492, 2011. http://dx.doi.org/10.1590/S0044-59672011000400006

MORIN, Edgar; Le MOIGNE, Jean-Louis. A inteligência da complexidade. São Paulo: Petrópolis, 2000.

OLIVEIRA, Verônica Macário de; CORREIA, Suzanne Érica Nóbrega; GOMEZ, Carla Regina Pasa. Cultura de consumo, sustentabilidade e práticas empresariais: como as empresas podem contribuir para promover o valor simbólico da sustentabilidade nas atividades de consumo? Revista de Gestão Ambiental e Sustentabilidade, São Paulo v. 5, n. 1, p. 61-77, 2016. http://dx.doi.org/10.5585/geas.v5i1.335

PÁDUA, Elisabete M. M. de. Complexidade e meio ambiente: um estudo sobre a contribuição de Edgard Morin. In: PÁDUA, Elisabete M. M. de; MATALLO JÚNIOR, Heitor (Orgs). Ciências sociais, complexidade e meio ambiente: interfaces e desafios. Campinas: Papirus, 2008, p. 15-46.

PORTO-GONÇALVES, Carlos Walter. O desafio ambiental. Rio de Janeiro: Record, 2004.

POTT, Crisla Maciel; ESTRELA, Carina Costa. Histórico ambiental: desastres ambientais e o despertar de um novo pensamento. Estudos Avançados, São Paulo, v. 31, n. 89, p. 271-283, 2017. http://dx.doi.org/10.1590/s0103-40142017.31890021

PRIGOGINE, llya. O fim das certezas: tempo, caos e as leis da natureza. São Paulo: Editora UNESP, 1996.

RODRIGUES, Arlete Moysés. Produção e consumo do e no espaço. Problemática ambiental urbana. São Paulo: Hucitec, 1998.

RODRÍGUEZ, Enrique Ortega. Análise crítica da Sustentabilidade e da Pegada Ecológica. In: WORKSHOP INTERNACIONAL DE PRODUÇÃO MAIS LIMPA, 3, 2011, São Paulo. Anais..

ROMEIRO, Ademar Ribeiro. Desenvolvimento sustentável: uma perspectiva econômico -ecológica. Estudos Avançados, São Paulo, v. 26, n. 74, p. 65-92, 2012. http://dx.doi. org/10.1590/S0103-40142012000100006

SACHS, Jeffrey. O fim da pobreza. Como acabar com a miséria mundial nos próximos vinte anos. São Paulo: Companhia das Letras, 2005.

SACHS, Ignacy. Rumo à ecossocioeconomia: teoria e prática do desenvolvimento. São Paulo: Cortez, 2007.

SACHS, Ignacy. Primeiras Intervenções. In: BECKER, Bertha; BUARQUE, Cristovam; NASCIMENTO, Elimar Pinheiro do. (Orgs.). Dilemas e desafios do desenvolvimento sustentável no Brasil. Rio de Janeiro: Garamond Universitária, 2009, p. 19-42.

SANTOS, Maria Helena de Castro. Governabilidade, governança e democracia: criação da capacidade governativa e relações executivo-legislativo no Brasil Pós-Constituinte. DADOS - Revista de Ciências Sociais, Rio de Janeiro, v. 40, n. 3, p. 335-376, 1997. http://dx.doi.org/10.1590/S0011-52581997000300003

SCHONS, Selma Maria. A questão ambiental e a condição da pobreza. Revista Katálysis, Florianópolis, v. 15, n. 1, 70-78, 2012.

SILVA, Marina. Mediação de Conflitos Socioambientais - Prefácio. In: THEODORO, Suzi Huff. (Org.). Mediação de conflitos socioambientais. Rio de Janeiro: Garamond 2005, p. 9-13.

SILVA, Maria das Graças e. Questão ambiental e desenvolvimento sustentável: um desafio ético-político ao Serviço Social. São Paulo: Cortez, 2010.

SILVA, Maria das Graças e. Sustentabilidade socioambiental e a retórica neodesen volvimentista: apontamentos sobre meio ambiente e saúde no Brasil. Revista Serviço Social e Sociedade, São Paulo, v. 123, p. 428-446, 2015. http://dx.doi.org/10.1590/0101. 6628.031

SOTTO, Debora; RIBEIRO, Djonathan Gomes; ABIKO, Alex Kenya; SAMPAIO, Carlos Alberto Cioce; NAVAS, Carlos Arturo; MARINS, Karin Regina de Castro; SOBRAL, Maria do Carmo Martins; PHILIPPI Jr., Arlindo; BUCKERIDGE, Marcos Silveira. Sustentabilidade urbana: dimensões conceituais e instrumentos legais de implementação. Estudos Avançados, v. 33, n. 97, p. 61-80, 2019. https://doi.org/10.1590/s0103Estudos Avançados, 


\section{Agradecimentos}

À Coordenação de Aperfeiçoamento de Pessoal de Nível Superior (CAPES), ao Programa de Suporte à Pós-Graduação de Instituições de Ensino Particulares (PROSUP) e à Universidade Anhanguera-Uniderp, pela bolsa de estudos concedida e equipamentos disponibilizados. Ao Conselho Nacional de Pesquisa (CNPq), pela bolsa de Produtividade em Pesquisa.

Emilia Alibio Oppliger

Universidade Anhanguera-Uniderp, Programa de Pós-Graduação em Meio Ambiente e Desenvolvimento Regional

Rua Alexandre Herculano, 1400, Jardim Veraneio, 79037-280, Campo

Grande, MS. Fone: (67) 3309-6565

https://orcid.org/0000-0002-8970-4025
Izabela Cristina Barbosa Prado de Souza Ronda

Universidade Anhanguera-Uniderp, Programa de Pós-Graduação em

Meio Ambiente e Desenvolvimento Regional

Rua Alexandre Herculano, 1400, Jardim Veraneio, 79037-280, Campo

Grande, MS. Fone: (67) 3309-6565

https://orcid.org/0000-0002-4047-0547

prado.izabela82@gmail.com

Ademir Kleber Morbeck de Oliveira

Universidade Anhanguera-Uniderp, Programa de Pós-Graduação em

Meio Ambiente e Desenvolvimento Regional

Rua Alexandre Herculano, 1400, Jardim Veraneio, 79037-280, Campo

Grande, MS. Fone: (67) 3309-6565

https://orcid.org/0000-0001-9373-9573

akmorbeckoliveira@gmail.com
Notas do Editor:

Data de submissão: 24/04/2020

Aceite: 30/06/2020

Revisão: RMO 